\title{
Development, comparative morphology and cornification of reptilian claws in relation to claws evolution in tetrapods
}

\author{
Lorenzo Alibardi ${ }^{1,2}$ \\ ${ }^{1}$ Dipartimento di Biologia evoluzionistica sperimentale, University of Bologna, Via Selmi 3, 40126 Bologna, Italy \\ ${ }^{2}$ E-mail: lorenzo.alibardi@unibo.it
}

Key words: autoradiography, claws, cornification, histogenesis, reptiles, ultrastructure

\begin{abstract}
The development of claws in different reptiles and their cornification are analyzed using histological, ultrastructural and autoradiographic methods. Claws develop at the tip of digits in relation to the growth of the terminal phalanx and appear as modified scales. The apical epidermis of digit becomes thickened and is associated with a mesenchymal condensation or a dense mesenchyme. The dorsal side of the digit becomes the unguis while the ventral side becomes the sub-unguis. The corneous layer in the unguis is thicker than in the sub-unguis and accumulates hard-keratin while corneocytes remain separated or partially fused. Bundles of hard-keratin tend to accumulate in parallel orientation with respect to the surface and are directed toward the claw tip. The sub-unguis is formed by a softer corneous material and by a much thinner hard-keratin layer. Autoradiography after tritiated thymidine and histidine injection indicates that the growth of reptilian claws occurs along the entire epidermis of the claw. A proximal matrix zone for cell proliferation like in mammalian nails and claws is therefore absent in claws of reptiles. This observation indicates that the pattern of growth of reptilian and probably avian claws is different from that of mammals.
\end{abstract}

\section{Contents}

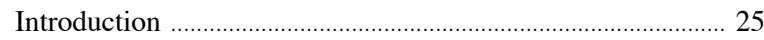

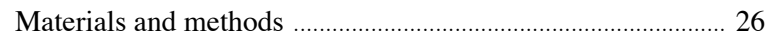

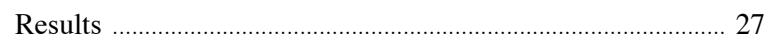

Macroscopic changes during claw morphogenesis

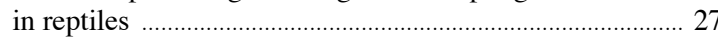

Lizard claw morphogenesis and epidermal

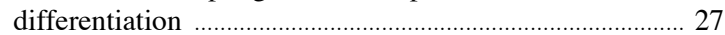

Formation of claws in the Tuatara .................................... 31

Morphogenesis and cornification in turtle claws ............... 35

Morphogenesis and cornification in claws of the

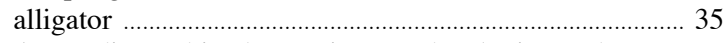

Autoradiographic observations on developing and

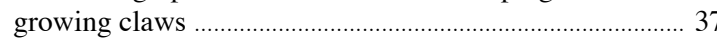

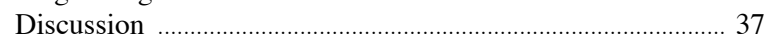

Claw formation and growth in reptiles .............................. 37

Cornification in reptilian claws in comparison to scales .. 40

Acknowledgements .................................................................. 41

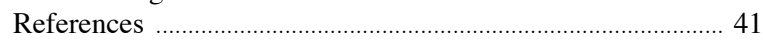

\section{Introduction}

Claws consist of pointed corneous derivatives of digital tips sustained by the last phalanx of the digit. They are present in most sauropsids (reptiles and birds), in numerous mammals, and in few amphibian species (Kreisa, 1979). The microscopic process of formation of claws and their homologous skin derivatives such as nails and hoofs, are known for only a few species of mammals (Hashimoto et al., 1966; Baden, 1970; Hashimoto, 1971; Kato, 1977; Baden and Kvedar, 1983; Chapman, 1986; De Berker and Angus, 1996; Bragulla, 2003; Bragulla and Hirshberg, 2003; Hamrich, 2003; Wu et al., 2004; Alibardi, 2009a).

Claws were likely present in early tetrapods of the Carboniferous (Maddin and Reisz, 2007) but recent studies suggest that the pattern of development and growth is different in claws of extant amphibians and amniotes (Maddin et al., 2007, 2008). Recent studies on lizard claws have further indicated that the pattern of development and growth in reptiles is probably also different in comparison to that present in mammals, such that specific differences are also present among different amniotes (Alibardi, 2008a, b; Alibardi and Toni, 2009). In fact, the morphogenesis and growth pattern of claws in the frog Xenopus laevis Daudin 1802 (Maddin et al., 2007, 2008), in a lizard (Alibardi, 2008a, b), and in the zebrafinch (Alibardi, 2009b), are different from those in mammals. In particular, the region of cell proliferation and growth of claws appears not to be localized in a proximal nail groove (matrix) like for mammalian claws, but dividing cells appear more evenly distributed along the epidermis of claws, from their proximal base to the tip.

During development of mammalian claws, a thickening of the epidermis in the dorsal tip of the digits is associated with a mesenchymal induction and condensation (Hamrich, 2001, 2003). Some structural information is available for adult avian claws (Kerr, 
1919; Lucas and Stettenheim, 1972; Spearman and Hardy, 1985), and only a recent study has shown the cytological details of the process (Alibardi, 2009a).

In reptiles, the modern representatives of the first amniotes, it is suggested that claws are modified scales (Kreisa, 1979; Wu et al., 2004; Alibardi, 2008a, b). The latter studies on the ultrastructure and morphogenesis of claws in lizards have indicated that the curved dorsal side of claws (unguis or furcula) derives from the modification of the outer scale surface of one or more terminal scales of the digit. Therefore, the modification of the reptilian scale to produce a claw has maintained the pattern of growth typical for normal scales (Maderson, 1985; Landmann, 1986; Alibardi, 1998, 2003, 2005). Although the morphogenesis of the lizard claw may also be similar in other reptiles, the process has not been documented in the recent literature for chelonians and crocodilians, or for other species of lizards.

The knowledge of the microscopic process of formation of the corneous layer in claws of reptiles is important to confirm a causal relationship between the terminal phalanx and claw morphogenesis. In fact, this inductive relationship appears to be present during the formation of mammalian claws (Hamrich, 2001, 2003). Moreover, the process of cornification of the claw can then be compared among different reptiles, with that of birds and mammals in order to analyze common aspects of the process in molecular terms.

The present study was performed to extend our knowledge on the process of claw formation to representatives of the main reptilian groups, lepidosaurians, chelonians and archosaurs. Based on the embryonic stages in the different reptiles analyzed here, the present study emphasizes the peculiar aspects of the process of cornification in reptilian and avian claws in relation to the process present in mammals.

\section{Materials and methods}

The available material was derived from embryos and some adults that were previously collected for the analysis of skin morphogenesis: details on the experimental and microscopic techniques are reported in the cited papers below.
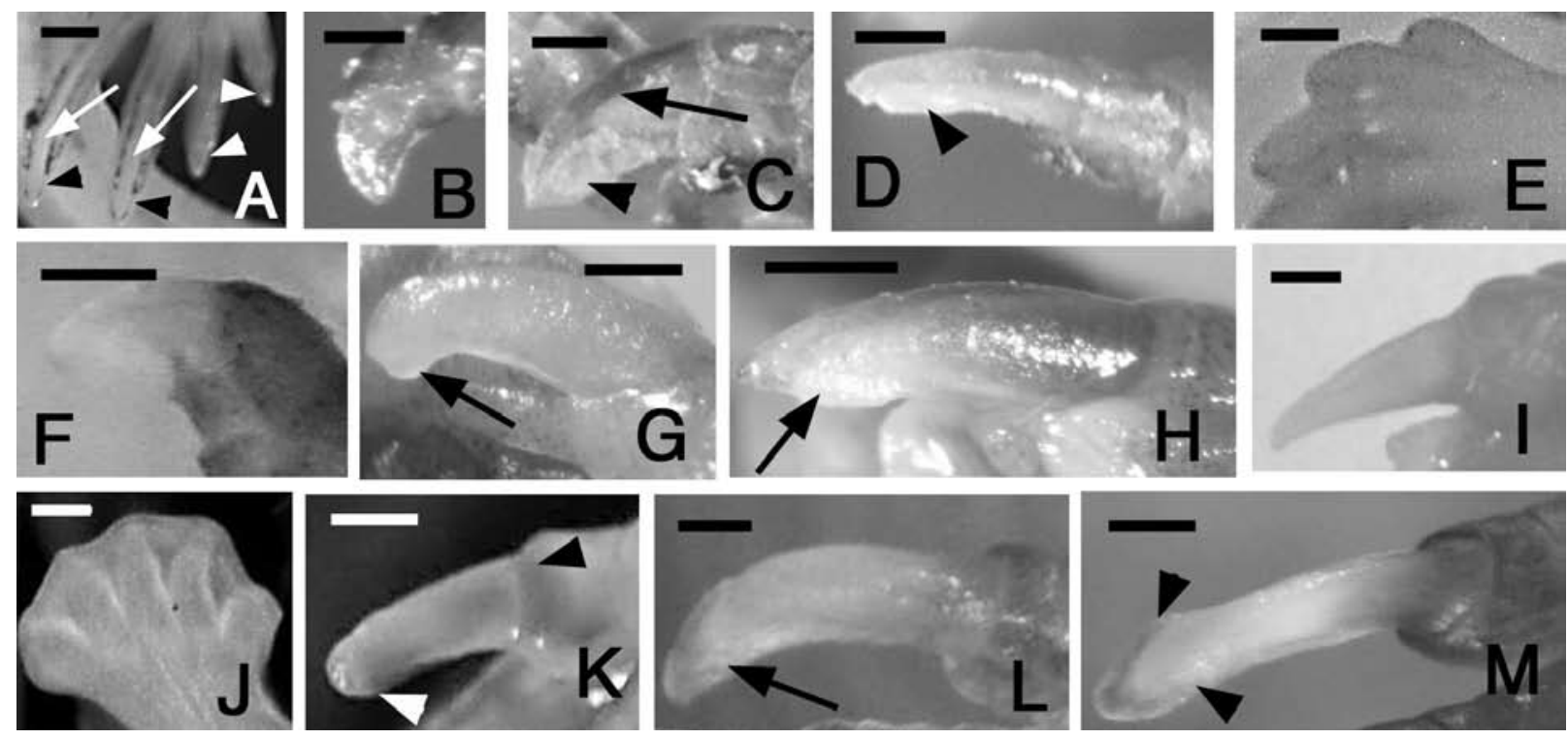

Fig. 1. Gross-morphological changes of the tip of the digits during claw formation in a lizard (L. delicata, A-D), a turtle (E. macquarii, E-I), and the alligator (A. missippippiensis, J-M). A, cone-like claws (arrowheads) at embryonic stage 36. Arrows indicate the phalanx as seen throughout the skin at this stage. Scale, $0.5 \mathrm{~mm}$. B, elongating cone with curving sub-unguis (arrowhead) at stage 38 . Scale, 0.25 $\mathrm{mm}$. C, elongating unguis (arrow) and forming apical-ventral pad (arrowhead) at stage 39. Scale, $0.25 \mathrm{~mm}$. D, long claw at stage 40 . The arrowhead indicates the small pad. Bar, $0.25 \mathrm{~mm}$. E, round digits at stage 18. Scale, $0.5 \mathrm{~mm}$. F, elongating claw (arrowhead) at stage 20. Scale $0.5 \mathrm{~mm}$. G, formation of the ventral claw pad (arrow) at stage 22. Bar, $0.5 \mathrm{~mm}$. H, elongating claw with pad (arrow) at stage 23. Scale, $1 \mathrm{~mm}$. I, formed pointed claw at stage 25 . Scale, $1 \mathrm{~mm}$. J, fingers with blunted tip (arrow) still united by the interdigital membrane at stage 19 . Scale, $0.5 \mathrm{~mm}$. K, elongating claw at stage 21 . The arrowhead points to the forming pad. Scale, $0.5 \mathrm{~mm}$. L, curving elongated claw at stage 22 (the arrow indicates the accumulating pad tissue). Scale, $0.5 \mathrm{~mm}$. M, latero-dorsal view of elongated claw at stage 23 with lateral pad tissue (arrowheads). Scale, $1 \mathrm{~mm}$. 
Briefly, late embryos of the Australian common skink Lampropholis guichenoti Dumeril and Bibron, 1839, (Scincidae, Squamata, embryonic stages corresponding to stages 34-40 in Lacerta vivipara, Jacquin 1787 , as described by Dufaure and Hubert, 1961) collected in a previous study on scale development (Alibardi and Thompson, 1999a), were utilized here for the study of claws.

Other claw samples derived from embryos of the lizard Anolis lineatopus Gray 1840, from adults of the gecko Hemidactylus turcicus Linneo 1758, and from adults of the turtle Chrysemys picta Schneider 1873. These animals were previously treated with tritiated histidine or tritiated thymidine for the study of keratin synthesis and cell proliferation in normal scales (see details in Alibardi, 1998, 2003, 2004b, 2005). The lizards and the turtle were injected with tritiated thymidine (5-6 $\mu \mathrm{Ci} / \mathrm{g}$ body weight), tritiated histidine (3-4 $\mu \mathrm{Ci} / \mathrm{g}$ body weight). Claw skin samples were collected and fixed 3 hours, 1 and 5-6 days post-injection (see details in the above cited references).

Embryos from the turtle Emydura macquarrii Gray 1831 (stages 18-25 according to Yntema, 1968, for Chelydra serpentina Linneo 1758), previously studied for scale morphogenesis (Alibardi and Thompson, 1999b), were used for the study on claw development. Also embryos of the American alligator (Alligator mississippiensis Daudin 1802) at stages 19-25 according to Ferguson (1987), previously analyzed for scale morphogenesis (Alibardi and Thompson, 2001), were further utilized for the study of claw development. Tissues were fixed for 8-12 hours in 2.5\% glutaraldehyde in $0.1 \mathrm{M}$ phosphate buffer at $\mathrm{pH} 7.4$. The tissues were post-fixed for 90 minutes with $2 \%$ osmium tetroxide, dehydrated in ethanol, infiltrated in propylene oxide for 1 hours, then in Epon resin for 16-24 hours at room temperature, and finally embedded in Epon resin at $60^{\circ} \mathrm{C}$ for two days.

Finally, few available stages from embryos of the tuatara (Sphenodon punctatus Gray 1842) corresponding to lizard stages, from 35-36 to 39-40, see Alibardi and Gill, 2007) were also analyzed in this study on claw development. The latter tissues were derived from embryos, fixed in formaldehyde and maintained in $70 \%$ ethanol in museum collections. Some sample claw tissues were re-fixed in $2.5 \%$ glutaraldehyde in $0.1 \mathrm{M}$ phosphate buffer at $\mathrm{pH} 7.2$, post-fixed for two hours at room temperature in $2 \%$ Os $\mathrm{O} 4$ in the buffer, dehydrated with ethanol, and embedded in Epon resin for ultrastructural analysis (see details in Alibardi and Gill, 2007).
Sections of 1-3 $\mu \mathrm{m}$ in thickness were obtained using an ultramicrotome, and were stained with $0.5 \%$ toludine blue and observed under light microcopy. From regions at the apex of digits, thin sections $(40-80 \mathrm{~nm}$ thick) were collected on copper grids, routinely stained with uranyl acetate and lead citrate, and observed under transmission electron microscope operating at 80$60 \mathrm{kV}$.

\section{Results}

Macroscopic changes during claw morphogenesis in reptiles

The gross morphology of developing claws in lizard, turtle, and alligator is exemplified in Fig. 1. In all cases, at the digit tip a round outgrowth is initially formed, which becomes conical and elongates mainly in the progressively curved dorsal side (unguis) while the ventral side (sub-unguis) remains linear or convex. Besides the specific curvature and size of the claw in each species, the shape of the developing claw tip is initially rounded and becomes more and more pointed approaching hatching. A ring-like fold appears at the base of the claw, delimiting the growing claw from proximal scales. While the unguis forms, in the apical and lateral part of the sub-unguis there is an accumulation of tissue that forms the claw pad or neonychium. The latter is a temporary tissue destined to be shed around hatching but it maintains the blunted shape of the claw tip, delaying the appearance of a sharp claw tip. In the lizard embryos (P. muralis Laurenti 1768, A. lineatopus Gray 1840, L. delicata De Vis 1888) the claws are conical and less elongated than in the tuatara S. punctaus, in the turtle E. macquarii, the tortoise Testudo hermanni Gmelin 1789, or the alligator A. missippippiensis.

The following descriptions deal with the histological and ultrastructural analysis of the main features that take place during claw morphogenesis in representative species of the main reptilian groups, lizards and tuatara (lepidosaurs), turtle (chelonians), and alligator (crocodilians).

\section{Lizard claw morphogenesis and epidermal differentia- tion}

During development in lizard embryos, digits become separated from inter-digital membranes around stage 35 according to Dufaure and Hubert (1961). At stages 


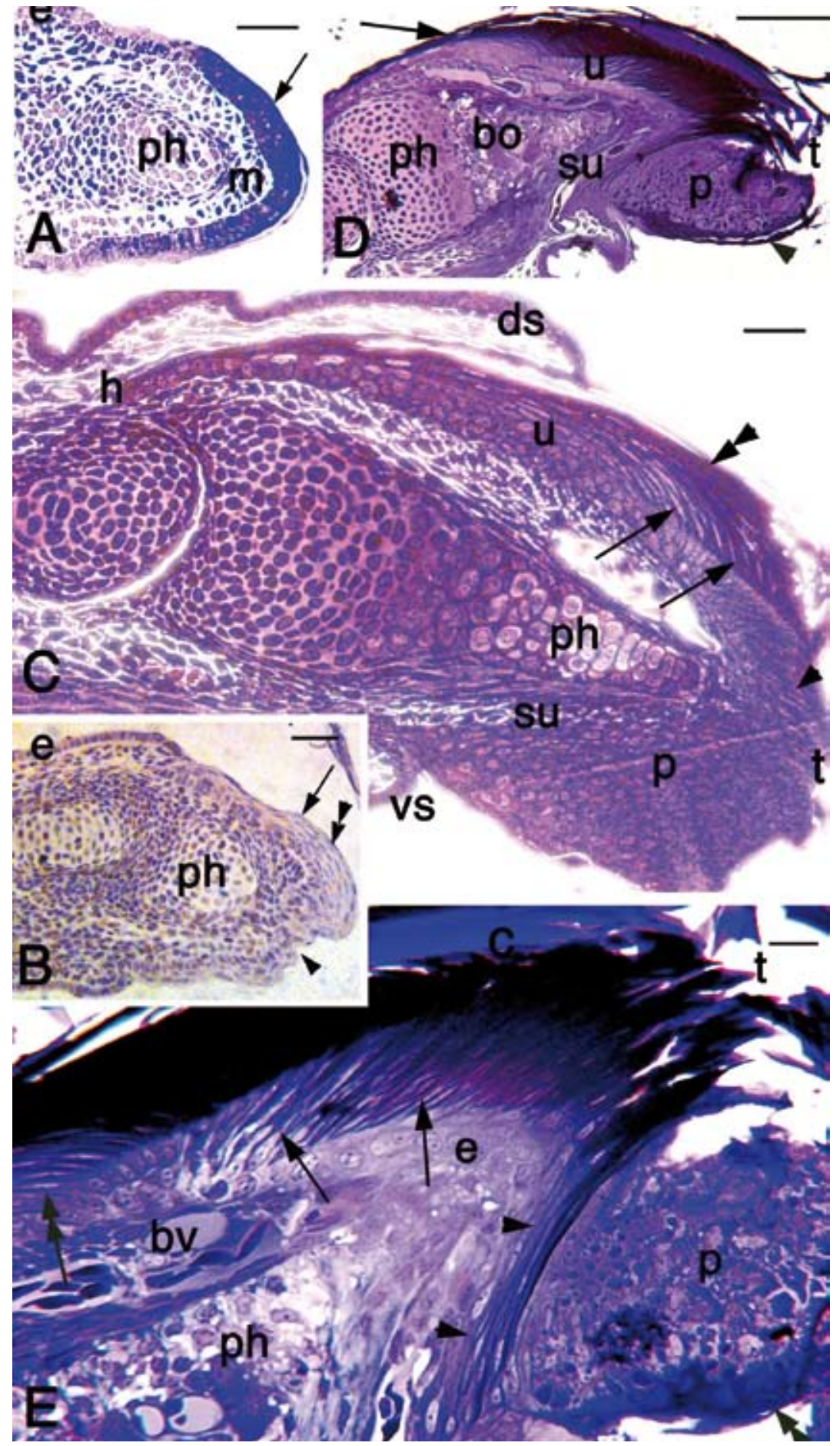

Fig. 2. Histological modifications of representative stages of developing claws in embryos of the lizard Anolis lineatopus. Toluidine blue stain. A, Longitudinal section of the tip at stage 34 featuring the thickened apical epithelium (arrow). Scale, $40 \mu \mathrm{m}$. B, elongating unguis (arrow) at stage 35 . The tip shows layers of stratified keratinocytes (double arrowhead), in part destined to form the claw pad. The arrowhead indicates the forming sub-unguis. Scale $20 \mu \mathrm{m}$. C, developing claw at stage 37 showing a large claw pad and a cartilaginous phalanx. In the unguis, elongating keratinocytes are directed backward (arrows) or forward (arrowhead). The double arrowhead points to the beginning of the corneous layer of the unguis. Scale, $30 \mu \mathrm{m}$. D, overview of the forming claw at stage 38 with a thick corneous layer in the unguis (arrow) and a thin corneous layer of the ventral pad (arrowhead) The terminal phalanx starts to turn into bone. Scale, $100 \mu \mathrm{m}$. E, detail of claw tip at stage 38 . Arrows indicate an elongated keratinizing cell pointing forward in the unguis while the double arrow indicates those pointing backward. Arrowheads indicate keratinocytes of the sub-unguis. The double arrowhead indicates the corneous layer covering the ventro-apical pad. 38 Scale, $10 \mu \mathrm{m}$. Legends: bo, bone forming in the phalanx; bv, blood vessel; c, corneous layer; ds, dorsal proximal scale; $\mathrm{e}$, epidermis; $\mathrm{h}$, hinge region (between claw and scale); m, apical mesenchyme; p, claw pad (neonychium); ph, palanx; su, sub-unguis; t, claw tip; u, unguis; vs, ventral proximal scale.

34 in Anolis lineatopus the tip of digits was covered by bi-layered epidermis, like in the remaining body. No scale anlagen were visible yet. However, the epidermis at the tip of the digit was thicker than in the other areas of the digit, and basal cells became elongated, like in a placode (Fig. 2A). The mesenchyme in front of the terminal phalanx was closely connected to this thickened epidermis, but typical mesenchymal condensations were not clearly seen.

At a later stage (35 and 36), the digital epidermis 
formed undulated or slanted curves along the surface, an indication of the formation of scales. However, the epidermis remained mainly bi-layered and few suprabasal cells were seen at this stage. Different from the more proximal regions, the epidermis of the dorsal part at the digit tip elongated and appeared thicker than in the non-apical epidermis, with 3-4 layers of flat suprabasal cells in the dorsal side covering the digital tip (Fig. 2B). At the very tip of the forming claw, a pad-like stratified tissue was present, forming a slightly folded cushion (double arrowheads in Fig. 2B). The ventral part of the tip of the digit was also thicker than the remaining epidermis, but it was less stratified than in the dorsal side. The mesenchyme beneath the thickened claw epidermis contained many cells and was in connection with the perichondrium of the terminal phalanx.

In the following stage (37), the skin of the digit was scaled and 1-2 suprabasal layers were present beneath the superficial, thin periderm. The terminal phalanx at this stage was still cartilaginous and reached the tip of the claw. The epidermis of the forming claws was much more complex at this stage than the other digit epidermis (Fig. 2C). In the dorsal side or unguis, the epidermis was made of a bi-layered stratum in the proximal (hinge) region, in continuity with the inner surface of the adjacent scale. Moving toward the tip of the digit, the epidermis progressively formed 3-5 layers of polygonal- to spindle-shaped cells in the external layers where keratinization occurred. In the distal regions of the unguis, the upper cells of this stratified epithelium appeared flat and elongated with their main axes oriented backward (arrows in Fig. 2C). The elongated cells appeared in continuation with the initial corneous layer of the unguis (double arrowhead in Fig. 2C). Other elongated cells, located near the tip of the unguis, were instead oriented with their main axis toward the tip of the claw (arrowhead in Fig. 2C). The latter cells were filled with filamentous material but appeared less differentiated than the backward-oriented cells.

The ventral epidermis forming the sub-unguis was composed of 2-3 layers of spindle-shaped or flat cells at this stage, and was apparently in continuation with an accumumlation of polygonal cells present at the ventral tip of the claw, indicated as the pad (Fig. 2C). This pad extended over the more apical region of the forming claw and was made of cells containing granulated material.

At stage 38 the claw was more elongated than in previous stages. The corneous layer of the unguis was thickened in comparison to the previous stage, and cells appeared more compacted into a dense corneous stratum (Fig. 2D). The stratum corneum of the unguis is derived from the agglutination of elongate and keratinized cells present in the transitional layer. Like in the previous stage, elongate cells at the tip of the claw were tilted forward forming the compact corneous tip of the claw (Fig. 2E, arrows).

Apparently the orientation of the main axes of these keratinizing cells changed in more proximal regions of the claw, as the axes turned backward (compare cells indicated by arrowheads versus those indicated by arrows in Fig. 2E). Also the epidermis of the more distal part of the sub-unguis appeared to be stratified, as indicated by the presence of 3-4 thin layers of elongated, keratinized cells, in continuation with those of the unguis (see arrowheads in Fig. 2E).

The large pad localized in the ventral side of the claw tip was composed of polygonal or irregular cells containing large granules with high affinity to toluidine blue (Fig. 2E). Also a sparse filamentous material was observed in the pad cells.

The ultrastructural analysis was specifically focused on the accumulation of keratin and corneous material in the elongating cells of the unguis and on cells of the ventral pad present at stage 37. Basal and suprabasal, polygonal-shaped cells contained sparse keratin filaments, but also in the elongating cells localized in the upper layer very few tonofilament bundles were seen (Fig. 3A, B). Cells were joined by numerous desmososmes and appeared elongated toward the surface of the epidermis. The next layer of keratinocytes consisted in elongated cells containing numerous, parallel bundles of dense keratin material surrounding the nucleus (Fig. $3 \mathrm{C})$. Examination of the apparently homogenous corneous material (see inset in Fig. 3B) at high magnification revealed the presence of the typical electron-lucid filaments of 3-4 nm among a thin denser matrix (i.e., the beta-keratin pattern, see Landmann, 1986). Keratin filaments increased in more external elongated cells while their plasma membrane appeared interrupted (Fig. 3D). In the external corneous layer, elongated cells were no longer separated one from another, and they were filled with parallel bundles of corneous material, among which groups of ribosomes were present (Fig. 3C). No other organelles were seen in these cells, including the large part of the plasma membranes and this tissue appeared to be formed by partially merged cells.

At this stage of development (37), the ventral pad of the claw tip appeared to be formed by irregularly displaced cells of the embryonic epidermis. The ultrastruc- 

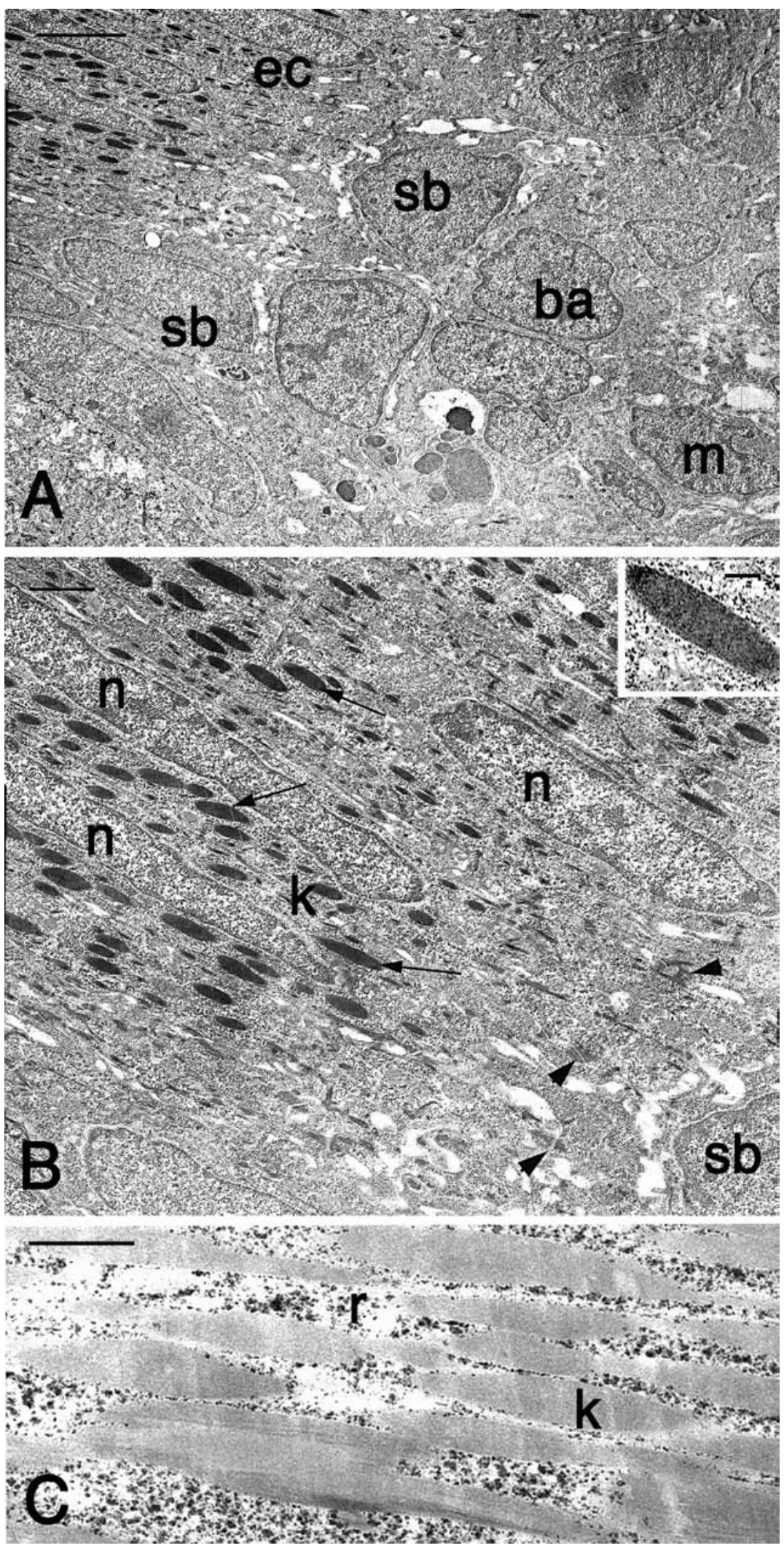

Fig. 3. Ultrastructural detail of differentiating cells in the epidermis of the unguis of claws in embryos of $A$. lineatopus at stage 37 (position as arrows in figure 1 C). A, basal cells are cubic and suprabasal cells elongate and accumulate bundles of keratin (arrows). Scale, $2.5 \mu \mathrm{m}$. B, detail of elongating cells to show the numerous and parallel (berta-)keratin bundles (arrows, see detail in the inset, Bar, $250 \mathrm{~nm}$ ). Arrowheads point to small (alpha-)keratin bundles. Scale, $1 \mu \mathrm{m}$. C, detail of the cytoplasm of elongating cell filled with large (beta-)keratin bundles and few ribosomes in between. Most of the plasma membrane in these cells have disappeared at this level. Scale, $0.5 \mu \mathrm{m}$. Legends: ba, basal cell; ec, elongating cell; $\mathrm{k}$, keratin bundle; $\mathrm{m}$, mesenchymal cell; $n$, nucleous; r, ribosomes; sb, suprabasal cell. 


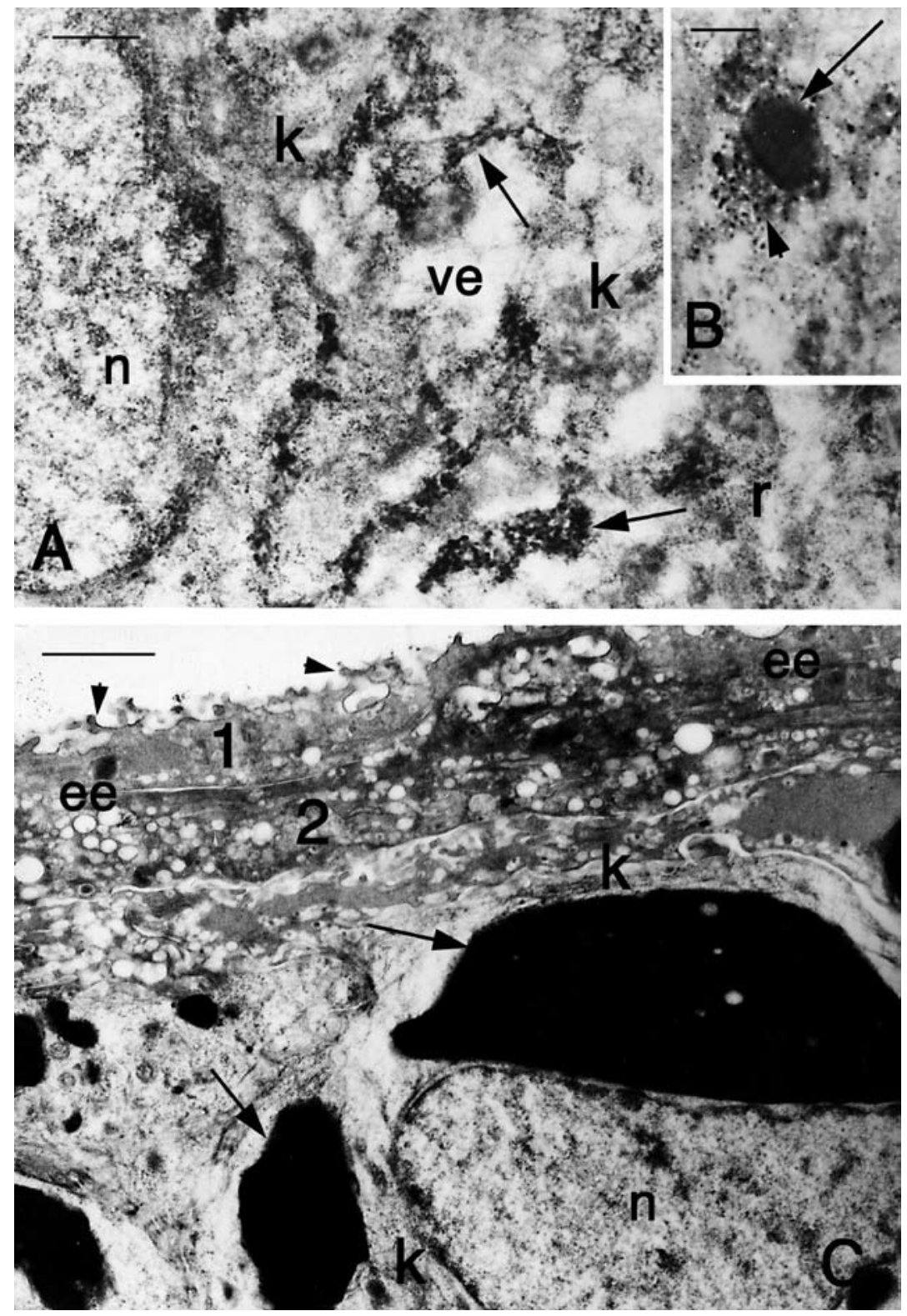

Fig. 4. Ultrastructural detail of the pad tissue in A. lineatopus at embryonic stage 37 (position as in figure 1-c). A, the vesicular cytoplasm contain sparse keratin mass, ribosomes, and dense organelles (arrows) made of a network of coarse filaments/granules. Scale, $0.5 \mu \mathrm{m}$. B, detail of a dense organelle (arrow) revealing distinct coarse filaments (arrowhead) in its peripheral region. Scale, $200 \mathrm{~nm}$. C, detail of the two first corneous layers (1 and 2) surrounding the claw pad. Microvilli (arrowheads) are present in the superficial (periderm) layer. Numerous vesicles are seen. The arrows indicate two large keratohyaline-like granules. Scale, $2 \mu \mathrm{m}$. Legends: ee, embryonic epidermis (first two layers); k, keratin material; $\mathrm{n}$, nucleous; $\mathrm{r}$, ribosomes (sparse); ve, vesicles.

tural analysis of the cells within the claw pad showed the presence of numerous and irregular aggregates of dense granules and coarse filaments of $20-30 \mathrm{~nm}$ in thickness (Fig. 4A). These filaments often surrounded or contacted (merging?) the dense granules (Fig. 4B).

The pad was surrounded by the external periderm and by two flat layers containing sparce tonofilaments and lipid-like or pale vesicles. The periderm layer contained microvilli and pale vesicles. Small keratohyaline-like granules $(0.1-0.5 \mu \mathrm{m})$ were seen in the external cells, while large keratohyaline-like granules $(0.1$ $2.5 \mu \mathrm{m}$ ) were present in the inner cells (Fig. 4C). The cytoplasm of the latter contained few other organelles. In particular sparse and short bundles of keratin filaments of $10 \mathrm{~nm}$ in diameter (alpha-keratin) were observed.

\section{Formation of claws in the Tuatara}

The available embryos from this rare species (S. punctatus, see Alibardi and Gill, 2007), allowed the evaluation of important comparative aspects with the developing claw observed in lizards. Like in lizards, the epidermis at the tip of digits in early stages (corre- 

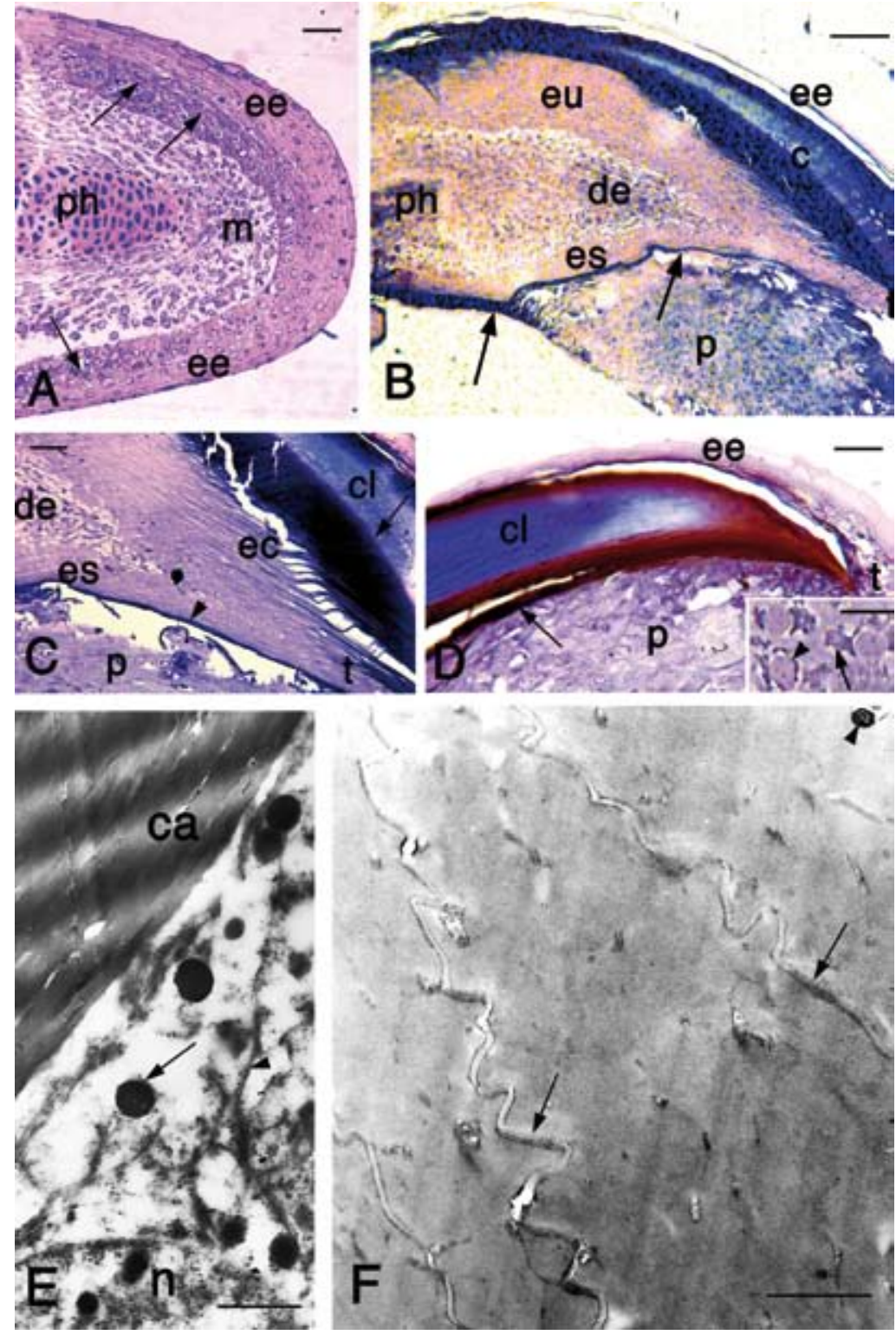

Fig. 5. Light microscopic (A-D, toluidine blue stain) and ultrastructural (E-F) images of three progressive stages of claw development in Sphenodon punctatus. A, frontal section of a developing claw in a relative early stage (corresponding to stage 36 in lizards). A stratified epidermis and a dense mesenchyme are present. Arrows indicate the initial differentiating cells beneath those of the embryonic layers. Scale, $25 \mu \mathrm{m}$. B, intermediate stage claw, roughly corresponding to that present at embryonic stage 39 in lizards. The corneous layers (compact pale and softer dark) of the unguis are quite thick in comparison to the thin layer present in sub-unguis (arrows). Scale, $50 \mu \mathrm{m}$. C, detail of the tip of the claw in the previous figure, showing the elongation of pre-corneous cells entering the dense corneous layer (arrow). The arrowhead indicates the thin corneous layer of the sub-unguis. Scale, $15 \mu \mathrm{m}$. D, apical part of a claw at a late stage, roughly corresponding to stage 40 in lizards. Most of the claw is made of the compact and pale corneous layer, but the sub-unguis is still coated by a softer keratin layer (arrow). Scale, $25 \mu \mathrm{m}$. The inset (Scale, $10 \mu \mathrm{m}$ ) shows the cellular aspect of the pad tissue. Arrowhead on a nuleous. The arrow indicates granular material in the cytoplasm. E, detail of transitional cells in the sub-unguis containing keratin bundles (arrowhead) and dense round granules (arrow). Embryo at an intermediate stage roughly corresponding to stage 39 in lizards. Scale, $1 \mu \mathrm{m}$. F, detail of cells of the corneous layer in the unguis at an intermediate stage. The perimeter of extremities of hardkeratin cells presents spiny protrusions connected by desmosomal remnants (arrows). Rare melanosomes are incorporated (arrowhead). Scale, $1 \mu \mathrm{m}$. Legends: c, corneous layer; ca, corneous (alpha-)layer; cl, compact corneous layer; de, dermis; ec, elongating (hard betakeratin) cells; ee, embryonic epidermis; es, epidermis of the sub-unguis; eu, epidermis of the unguis; m, apical mesnechyme; $n$, nucleous; $p$, claw pad; ph, phalanx; t, claw tip. sponding to embryonic stage 36 in lizards) was more stratified than in the remaining epidermis of the digit. The epidermis comprised 3-5 intermediate cell layers above the basal layer, followed by 3-4 flat layers of embryonic epidermis on the surface (Fig. 5A). In the available material, the underlying mesenchyme, located in front of the terminal phalanx, appeared slightly condensed. Cells of the basal layer of the epidermis at the tip of the claw were more columnar, while basal cells of non-apical regions tended to be more cubic.

In the next stage available, interpreted as an inter- mediate developing stage (corresponding to stage 38 of a lizard), the morphogenesis of the claw was largely completed (Fig. 5B-C). Intermediate stages showing more details of the morphogenesis of the claw, in particular documenting the progressive formation of unguis and sub-unguis in this species, were not available. Despite the shortcomings, the claw at this stage showed a thick corneous layer in the unguis, a thin corneous layer in the sub-unguis, and the presence of a cellular ventral pad near the tip of the claw, like that in lizards. 

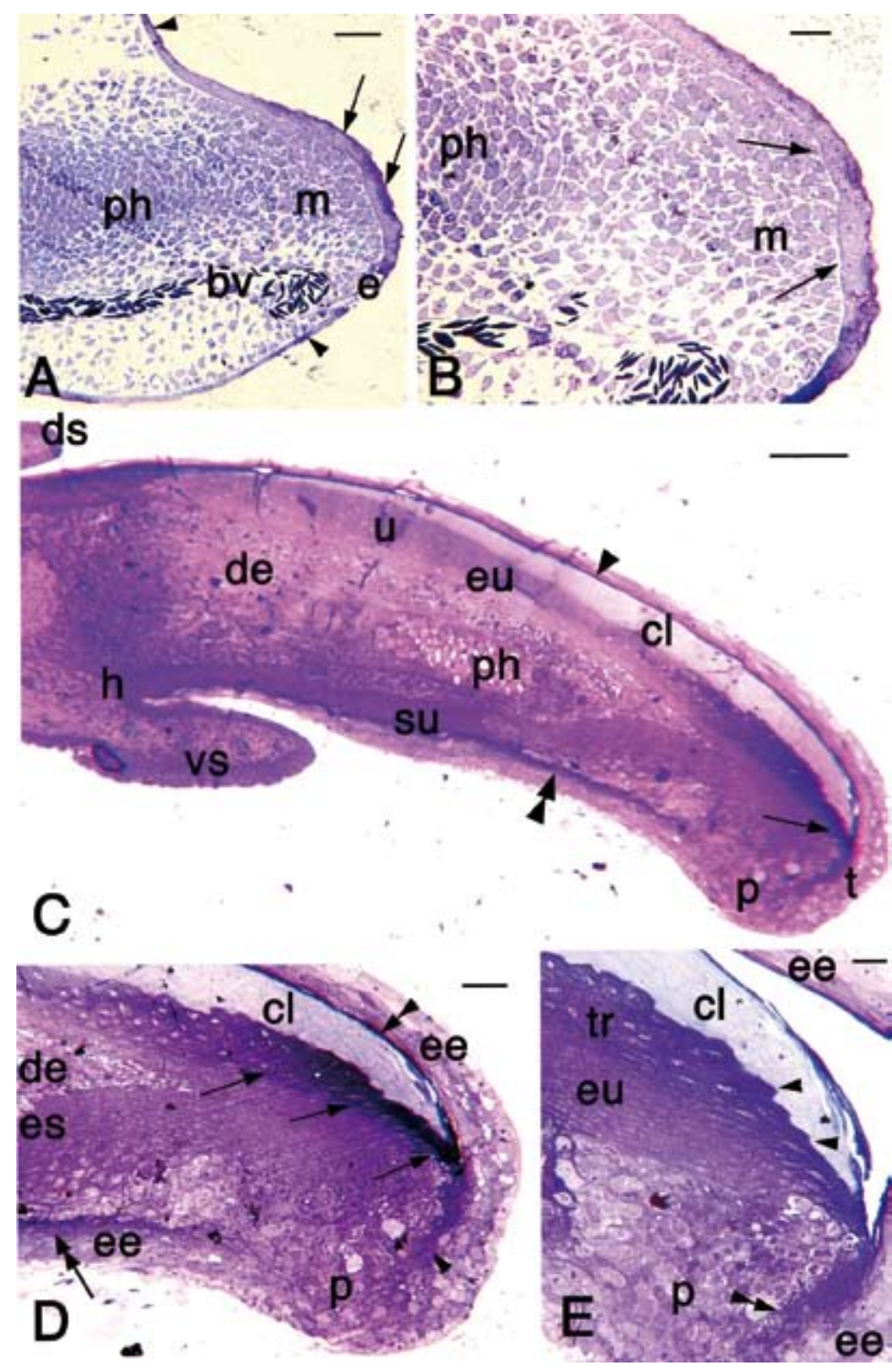

Fig. 6. Light microscopic views of developing claws in the turtle Emydura macquarii (Toluidine blue stain). A, digit tip (toe) with axial phalanx and an apical mesenchymal condensation localized near the epidermal thickening (arrows) at stage 18. Arrowheads indicate the thinner non-apical epithelium. Scale, $40 \mu \mathrm{m}$. B, detail of apical digit tip at stage 18. Arrows indicate the close contact between apical mesenchyme and the thickened epithelium. Scale, $20 \mu \mathrm{m}$. C, elongated claw at stage 22 . The ventral proximal scale is more advanced than the dorsal proximal scale. A large part of the thick unguis epidermis is occupied by a pale, compact corneous layer that thins out at the tip of the claw (arrow). Scale, $100 \mu \mathrm{m}$. D, detail of the tip of claw at stage 22 to show that the embryonic epidermis is continuous with the claw pad epidermis. The compact corneous cells (double arrowhead) are also continue in the ventral part of the claw tip (arrowhead), and with the dark, differentiating cells of the unguis epidermis (arrows). A thin layer of corneous cells (double arrow) is present in the sub-unguis. Scale, $20 \mu \mathrm{m}$. E, close-up to the very tip of claw at stage 22 showing the sawlike outline (arrowheads) of the cells incorporated in the compact stratum corneum. The more advanced hard-keratin cells (double arrowhead) form a dark, curved line below the embryonic epidermis, and are directed to the ventral side of the claw tip. Scale, $10 \mu \mathrm{m}$. Legends: bv, blood vessel; cl, compact (hard beta-keratin) layer; de, dermis; ds, dorsal proximal scale; ee, embryonic epidermis; es, epidermis of the sub-unguis (tangentially sectioned); eu, epidermis of the unguis; $h$, hinge region; $\mathrm{m}$, apical (condensed) mesenchyme; p, claw pad; ph, cartilaginous terminal phalanx; su, sub-unguis; t, claw tip; $\mathrm{u}$, unguis; tr, transitional layer (hard-keratin cells); vs, ventral proximal scale.
The observation of the epidermis of the unguis at higher magnification showed elongated fusiform cells in the transitional layers containing filaments of stained material, in contact with the dense corneous layer (Fig. 5C). These keratinizing cells maintained their perimeter after incorporation into the corneous layer where they stick together as a compact mass. The external part of the corneous layer appeared pale and its cell structure was not clearly visible. This indicated that cornified cells in part maintain their identity also in the outer, paler stratum corneum. Finally, the outermost embryonic epidermis was formed of a dark stratum of elongated cells.

The ventral claw pad was composed of an accumulation of pale cells storing granular material, similar to those of the thinner embryonic epidermis covering the unguis.

The final stage available, a late embryo probably close to hatching (corresponding to stage 40 in a lizard, see Alibardi and Gill, 2007) showed a compact corneous layer formed by agglutinated cells (Fig. 5D). The ventral pad contained large and pale cells, some of 

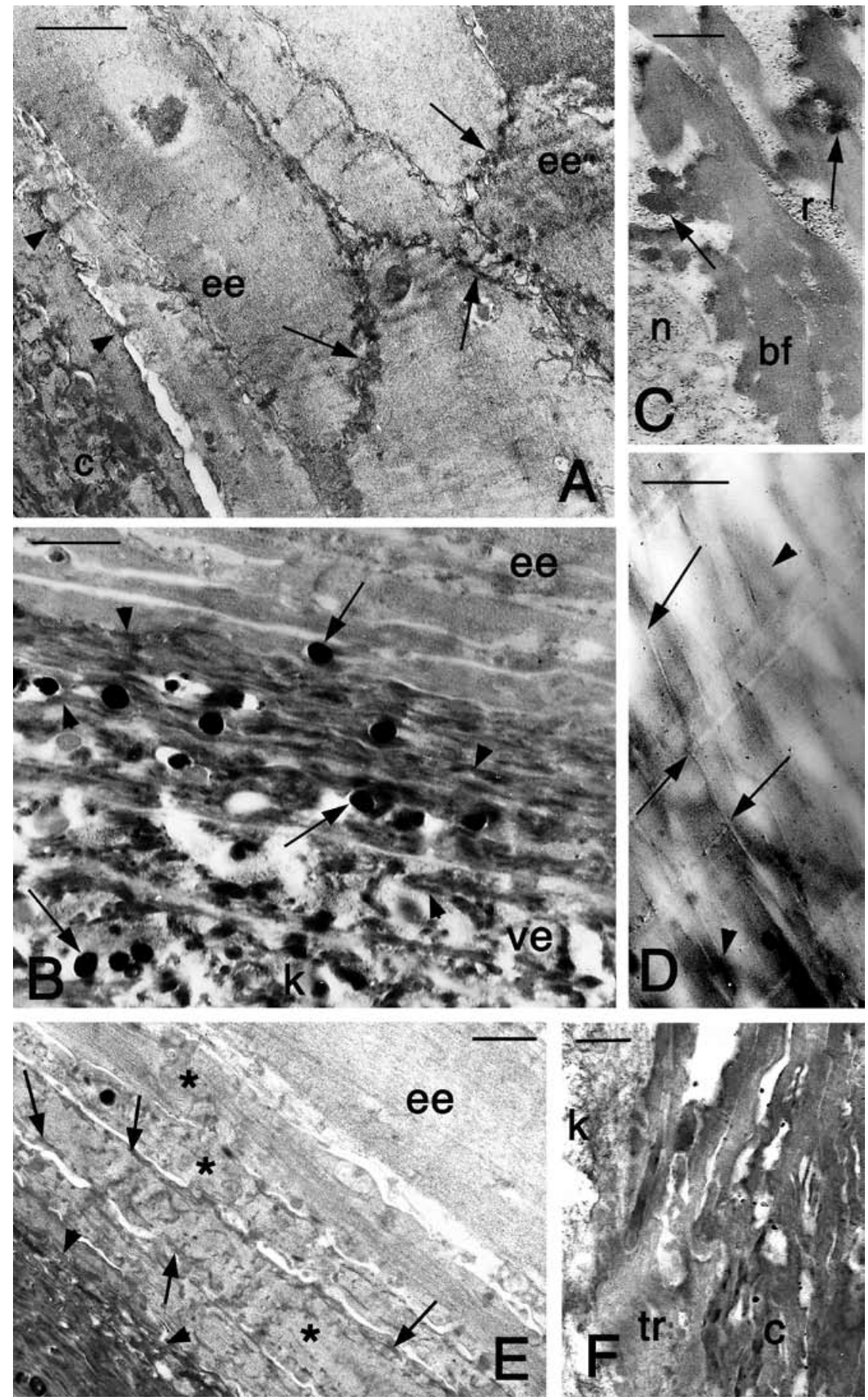

Fig. 7. Ultrastructural details of claws in the turtle E. macquarii. A, detail of the irregular perimeter (arrows) of the cells of the embryonic epidermis at stage 22. Desmosomes (arrowheads) connect the embryonic cells to the initial corneous cells of the unguis. Scale, $2.5 \mu \mathrm{m}$. B, transitional cells between embryonic epidermis and corneoeus layer of the unguis at stage 23. Numerous alphakeratin bundles (arrowheads) and some melanosomes (arrows) are incorporated in these cells. Bar, $1 \mu \mathrm{m}$. C, detail of hard-keratin bundles (arrows) among free ribosomes in differentiating keratinocyte of the unguis at stage 23. Scale, $0.5 \mu \mathrm{m}$. D, detail of compact pale corneous layer of the unguis at stage 23 . Boundaries among cells are partially visible. Arrowheads indicate denser areas among pale areas of mature corneocytes. Scale, $0.5 \mu \mathrm{m}$. E, detail of passage layers (asterisks) between embryonic and differentiating corneocytes of the sub-unguis (arrowhead) at stage 22 . Arrows indicate the initial concentration of alphakeratin bundles along the cell perimeter. Scale, $2 \mu \mathrm{m}$. F, detail of transitional cells in the sub-unguis at stage 23. Scale, $1 \mu \mathrm{m}$. Legends: ak, alphakeratin bundles; bf, hard (beta)-keratin filament bundles; $\mathrm{c}$, thin alphakeratin cells of the corneous layer of the sub-unguis; ee, embryonic epidermis; k, alpha-keratin bundles; $n$, nucleus; r, ribosomes; tr, tansitional cells; ve, pale vesicles. which were probably degenerated (pycnotic nuclei). However, most of the polygonal and pale cells of the pad, probably already keratinized, contained coarse granular material or large granules (inset of Fig. 5).

The ultrastructural examination of the epidermis of the sub-unguis in the sample of the intermediate em- bryonic stage, showed the presence of transitional cells containing a vesicular, probably artifact pale cytoplasm, sparse keratin bundles and round, dense keratohyalin-like granules of $0.1-0.3 \mu \mathrm{m}$ in diameter (Fig. $5 \mathrm{E})$. Corneocytes of the stratum corneum in the subunguis were thin $(0.2-0.4 \mu \mathrm{m})$ and electrondense, with 
a relatively smooth border, as typical for alpha-keratinocytes. In the unguis, corneous cells were larger, electron-pale, and spindle-shaped. The corneocytes showed a spiny surface, especially in their spindleshaped endings that determine a tight cell connectivity within this hard corneous layer (Fig. 5F). Corneocytes were largely separated in the stratum corneum of the unguis, and their thickened cell membranes were connected by desmosomal remnants.

\section{Morphogenesis and cornification in turtle claws}

The developing digits at stage 18 often showed a mesenchymal condensation in front of the phalanx and beneath the apical, columnar epithelium of the digit tip (Fig. 6A, B). The perichondrion of the phalanx was in contact with the apical mesenchyme, which cells showed a close link with the placode-like, apical epithelium.

Intermediate, embryonic stages (19-21), were not available. At stage 22 the claw was elongated and a thick, and a pale corneous layer was formed in the unguis but was absent in the sub-unguis (Fig. 6C). Also in this case the terminal phalanx, composed of ossifying cartilage, approached the tip of the claw. The unguis epidermis was composed of a basal layer, 3-5 suprabasal layers of fusiform cells, and by 4-6 layers of darkly stained spindle-shaped keratinocytes (Fig. 6D). The latter formed an irregular, sometimes jig-saw like border with the pale and compact corneous layer located beneath 4-6 layers of pale cells of the embryonic epidermis (Fig. 6E). The latter extended over the tip of the claw and formed a pad in the ventral side of the apical part of the claw which was continuous with the embryonic epidermis of the sub-unguis.

A dark, thin corneous layer was present in the subunguis while a thin, pale corneous layer was absent or very thin at this stage (22). However, a thin pale and hard layer was formed in the sub-unguis at later stages of embryogenesis and was also present in adult claws (data not shown).

The ultrastructural analysis showed the irregular cell boundaries present among keratinocytes of the embryonic epidermis, which cells were filled with numerous keratin filaments (Fig. 7A). The underlying corneous layer was formed by corneocytes with a cytoplasm filled with corneous material, which showed pale and dense areas. The perimeter of these thin corneocytes was less irregular than that observed among cells of the embryonic epidermis, and showed numerous desmosomes.
At stage 23, transitional cells of the stratum corneum (those stained with toluidine blue in light microscopic observation) appeared to contain sparse keratin bundles together with dark granules of $0.2-0.3 \mu \mathrm{m}$ and some pale vesicles (Fig. 7B). The higher magnification of the keratin bundles revealed that they were composed of irregular material with the characteristics of hard-keratin, surrounded by ribosomes. At high magnification the corneous material was made of 3-4 nm electron-lucid filaments among a scarce denser matrix, like in the compact corneous layer (Fig. 7C, D). In the mature corneous layer, desmosomal remnants were seen among cells. Cell boundaries among pale corneocytes were not complete, indicating a partial process of fusion among corneocytes.

In the sub-unguis at stage 23 , two main regions were seen, one distal region closer to the tip, and a more proximal region located toward the ventral fold between sub-unguis and the next ventral scale. In the more apical part of the sub-unguis, beneath 3-5 layers of embryonic epidermis similar to that present over the unguis, 0.6$1.5 \mu \mathrm{m}$ thin corneocytes were seen (Fig. 7E). Most tonofilaments (alpha-keratin) were localized along the plasma membrane while the central cytoplasm was pale, perhaps containing lipid material. Occasional cell organelles were present in corneocytes at this stage.

The medio-proximal region, occupying most of the sub-unguis except the zones near the tip, was made of thin alpha-keratin corneocytes $(0.4-0.6 \mu \mathrm{m})$ with irregular and interlocked surface (Fig. 7F). Pre-corneous cells contained numerous but thin bundles of alphakeratin filaments among empty spaces probably occupied by lipid material.

\section{Morphogenesis and cornification in claws of the alli- gator}

The digit at stage 19 was mainly composed of a twolayered epidermis where few suprabasal cells were seen. The mesenchyme was denser toward the tip of the digit (Fig. 8A) where a pre-cartilaginous condensation was seen, and the epidermis formed an apical thickening in this region.

At stage 20 the cartilaginous terminal phalanx was surrounded by a thickened epidermis (2 layers of suprabasal cells beneath the flat periderm) at the tip of digits (Fig. 8B). Dorsal and a ventral grooves were formed at the base of the claw.

At stage 21 the claw was much elongated and supported by a terminal phalanx composed of numerous hypertophic cartilaginous cells, which was surround- 


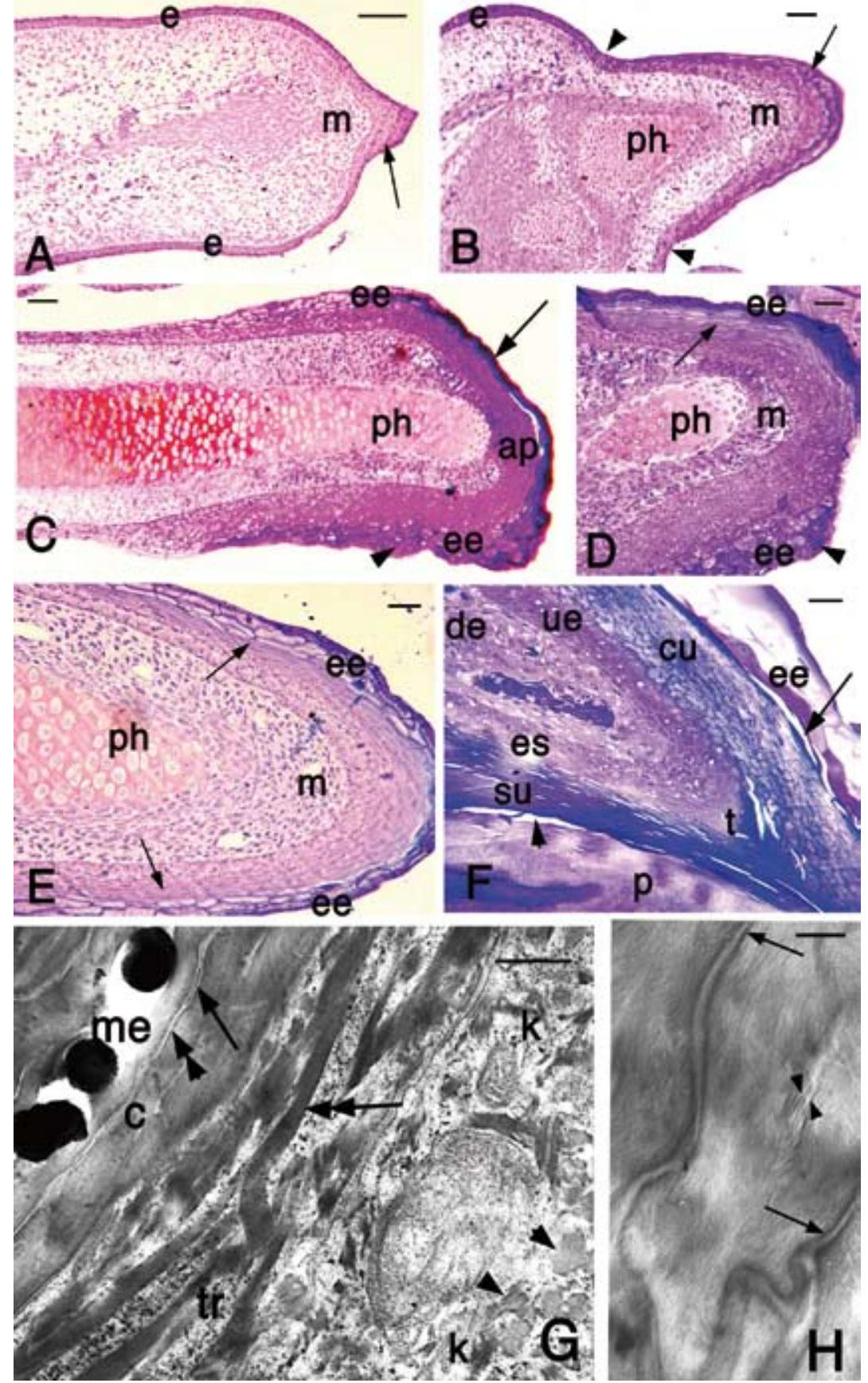

Fig. 8. Light (A-F) and ultratructural (G) features of developing claw in Alligator mississippiensis. A, elongating digit with a nearly apical epidermis (arrow) at stage 20 . Scale, $50 \mu \mathrm{m}$. B , formation of proximal claw hinge regions (arrowheads) at stage 20. The thickened epidermis at the claw tip shows the cornifying cells of the embryonic epidermis (arrow). Scale, 20 $\mu \mathrm{m}$. C, apical part of a long claw at stage 21 . The unguis (arrow) is elongating while embryonic cell form the claw pad (arrowhead). Scale, $25 \mu \mathrm{m}$. D, detail of the apical part of the claw at stage 21 with initial hard-keratin cells (arrow) accumulating underneath the embryonic layers. The arrowhead points to keratinizing cells of the claw pad. Scale, $20 \mu \mathrm{m}$. E, frontal section of developing claw at stage 22 showing flat differentiating hard-keratin cells (arrows) beneath the embryonic layers. Scale, $25 \mu \mathrm{m}$. F, detail of the claw tip at stage 23 . The arrow indicate the transition layer between the embryonic epidermis and the definitive corneous layer. The arrowhead shows the boundary between pad cells and sub-unguis corneous layer. Scale, $25 \mu \mathrm{m}$. G, ultrastructural detail of transitional cell and corneous cells in the unguis at stage 25. Hard(Beta)-keratin packets (arrowheads) are packed in long filaments (double arrow) that merge into a compact corneous material. The arrow indicates a desmosomal remnant. The double arrowhead indicates the thickened plasma membrane. Scale, $250 \mathrm{~nm}$. H, detail of corneocytes of the unguis at stage 25. The arrows indicate the thickened plasma membrane. Arrowheads point to keratin filaments among amorphous coneous material. Scale, $200 \mathrm{~nm}$. Legends: ap, apical epidermis; c, corneous layer; cu, corneous layer (cellular) of the unguis; de, dermis; e, epidermis; ee, embryonic epidermis; es, epidermis of the sub-unguis; $k$, alpha-keratin bundles; $\mathrm{m}$, apical mesnechyme; me, melanophores; p, claw pad; $\mathrm{ph}$, cartilaginous terminal phalanx; su, corneous layer of the sub-unguis; $t$, claw tip; tr, trasnitional layer/cell; u, unguis; ue, epidermis of the unguis. ed by a relatively denser mesenchyme at the tip of the claw (Fig. 8C-D). The epidermis of the forming claw was much thicker than in the remaining epidermis of the digit. In fact, beneath the flat periderm, 6-8 layers of keratinocytes were seen, and the more superficial 2-3 layers were made of fusiform and large pale cells of the embryonic epidermis, which will be shed at hatching. At the very tip of the claw, the epidermis showed a corneous layer that extended from the dorsal (unguis) to the ventral (sub-unguis) side of the forming claw. Also, at this stage in the apical part of the sub-unguis, the embryonic epidermis formed an apical pad (Fig. 8C, D). Beneath the embryonic epidermis, some layers of flat cells indicated the differen- 
tiation of the first cells containing hard keratin (Fig. $8 \mathrm{E})$. At this stage, no cells containing hard keratin were observed in the scales of other regions of the embryo.

At stage 22 the thickness of the living part of the epidermis of the claw remained the same as the previous stage, but the corneous layer became thicker (data not shown). At stage 23 the thick corneous layer of the unguis was paler and contained corneocytes still separated from each other. In contrast, the darker and thinner layer of the sub-unguis was made of 6-10 layers of thin and intensely stained corneocytes that were in continuation with the paler corneocytes of the unguis at the claw tip (Fig. 8F). The more external layer over the unguis was composed of corneous cells of the embryonic epidermis.

In the corneous layer of the sub-unguis, cells appeared flat and sometimes frayed upon sectioning. In the apical part of the sub-unguis, close to the pointed tip, a corneous mass of cells of the embryonic epidermis formed the ventral pad, superficial to the corneous layer of the sub-unguis.

The ultrastructural examination of the corneous cells of the unguis showed that they were filled with a mass of corneous material of low density, mixed with denser areas (Fig. 8G). In transitional cells packets these filaments were observed, while in lower layers, smaller filaments or smaller hard(beta)-keratin packets were present among the sparse alpha-keratin bundles. The cell membrane of mature corneocytes, 0.3-0.8 $\mu \mathrm{m}$ thick, appeared irregularly thickened $(15-30 \mathrm{~nm})$ by the deposition of a dense material along the plasma membrane (Fig. 8H). Desmosomal remnants were commonly seen among these corneous cells.

The examination of the cells of the epidermis of the sub-unguis revealed the formation of numerous hard(beta)-keratin packets in transitional cells while mature corneocytes appeared relatively thin and surrounded by a thickened, dense plasma membrane.

\section{Autoradiographic observations on developing and growing claws}

Only a qualitative description on sites of labeling within late developed claws and in adult claws is presented here. The aim is to show the main sites of cell proliferation (thymidine incorporation) and protein synthesis (histidine incorporation) in the claw epidermis of lizards and a turtle.

The developing claw of the iguanid lizard A. lineatopus at late stage of development (37) showed tritiated thymidine-labeled nuclei after 1 and 6 days from injection (Fig. 9A). At both these periods, labeled cells were not localized in a specific area of the epithelium of claws but were present along most epidermis, including the tip.

After 3 hours from the injection of tritiated histidine, the entire epidermis of the claw in the gecko $H$. turcicus was labeled, from the ventral hinge regions to the most dorsal part of the unguis of the claw (Fig. 9B, C). Most silver grains were seen in the upper layers of the epidermis and in the transitional layer, and often a higher labeling was seen toward the claw tip. An even labeling pattern was also seen in the surrounding scales (data not shown).

After one day post-injection of tritiated thymidine in the turtle $C$. picta, labeled cells were present along the basal layer of the entire epidermis, from the proximal hinge regions at the base of the claw to the unguis or dorsal side. Labeled nuclei were commonly seen in the epidermis of the sub-unguis and also in the epidermis at the tip of the claw (Fig. 9D-F). Thymidine-labeled nuclei were seen dispersed along most of the basal layer and occasionally in suprabasal layers of the epidermis of the claw of this turtle. No labeled nuclei were present in the transitional and corneous layer at 1 day post-injection, but labeled cells located above the basal layer were observed at 5-6 days post-injection (data not shown).

\section{Discussion}

\section{Claw formation and growth in reptiles}

The drawings presented in Fig. 10A and B summarise two different interpretations on claw formation in reptiles. In Fig. 10A-A3, from a symmetric, terminal scale at the digital tip in early embryonic stages (closely surrounding the terminal phalanx), the dorsal side of the scale expands distally and laterally more than the ventral side. Fig. 10B-B3 shows that the terminal area of the digit is occupied by an extended hinge region, located between the dorsal and the ventral scales. According to this interpretation, it is the prevalent growth of the dorsal scale over the ventral scale, both distally and laterally, that determines the coverage of the digital apex by cells derived from the unguis and that also forms part of the sub-unguis (curved arrows in Fig. 10A1-2 and B1-2).

The pattern of uptake of histidine in claws, that is connected to the synthesis of keratin, and the pattern of uptake of thymidine, indicating main areas of cell 

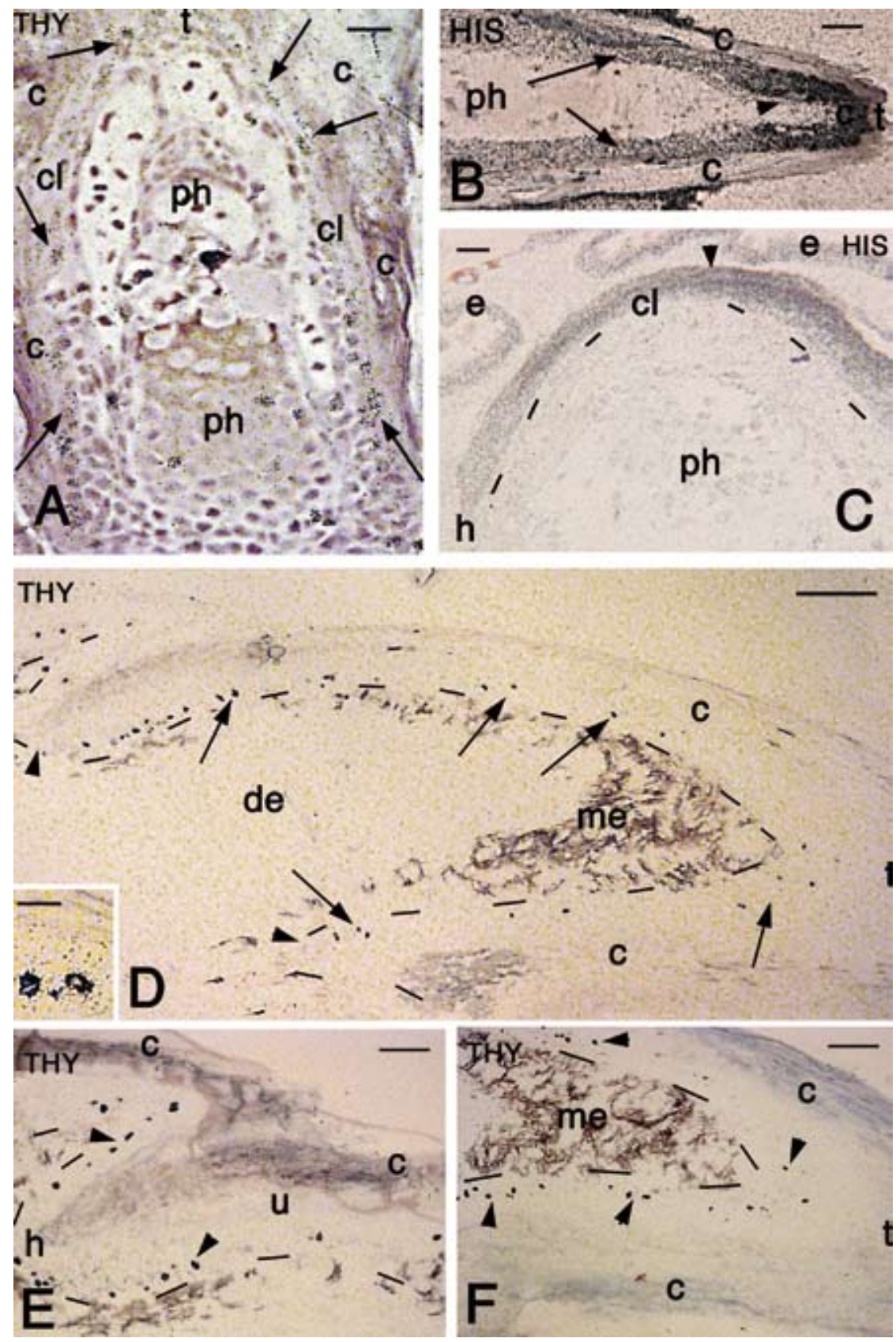

Fig. 9. Light autoradiographic images of claws of an embryonic lizard A. lineatopus $(\mathbf{A})$, an adult gecko $H$. turcicus $(\mathbf{B}, \mathbf{C})$, and an adult turtle (C. picta, D-F). A, frontal section of claw autoradiography at stage 37 . Six days after injection of tritiated thymidine (THY) most epidermal cells are labeled (arrows). Scale, 20 $\mu \mathrm{m}$. B, frontal-section of a digit at 3 hours post-injection of tritiated histidine. The epidermis is evenly labeled (arrows) but a denser labeling is seen at the tip (arrowhead). Scale, $15 \mu \mathrm{m}$. $\mathbf{C}$, detail of the evenly labeled unguis epidermis in cross section (arrowhead on the top indicates the dorsal part) 3 hours post-injection of tritiated histidine (HIS). A reduced labeling is present in the hinge region. Scale, $30 \mu \mathrm{m}$. D, longitudianl section of turtle claw 1 days after injection of tritiated thymidine. Labeled nuclei (two are enlarged in the inset, Scale, $15 \mu \mathrm{m}$ ) are present along the entire epidermis (arrows), including the proximal dorsal and ventral hinge regions (arrowheads). Bar, $100 \mu \mathrm{m}$. E, detail of labeled nuclei (arrowheads) in the dorsal hinge region 1 days post-injection of tritiated thymidine. Scale, $30 \mu \mathrm{m}$. F, detail of tritiated thymidine labeled nuclei (arrowheads) located by the apex of the claw one day after injection. Scale, $30 \mu \mathrm{m}$. Legends: c, corneous layer; cl, claw epidermis; de, dermis; e, epidermis (normal scales); $\mathrm{h}$, hinge region; me, melanophores; ph, palanx; t, tip fo the claw; u, unguis; Dashes underline the epidermis. proliferation, are different from the pattern of proliferation present in mammalian nails (Zaias and Alvarez, 1968; De Becker and Angus, 1996). In fact, in reptilian claws thymidine-labeled nuclei are present along the entire epidermis of the claw, and are not localized in proximal, matrix zones like in mammalian nails/claws (Fig. 10, compare C3 and C7). Also, the even labeling of the claw epidermis after injection of tritiated amino acids, with a prevalent labeling near the tip of reptilian claws, is different from that of mammals, where most labeling is localized in matrix regions and moves gradually distally (Zaias and Alvarez, 1968). The results derived from the present observation with triated histidine suggests that, like in scales, no localized matrix regions (germinative) are present in reptilian claws. This is also confirmed using tritiated proline (Alibardi, personal observations). This autoradiographic labeling is different with the labeling previously observed in 

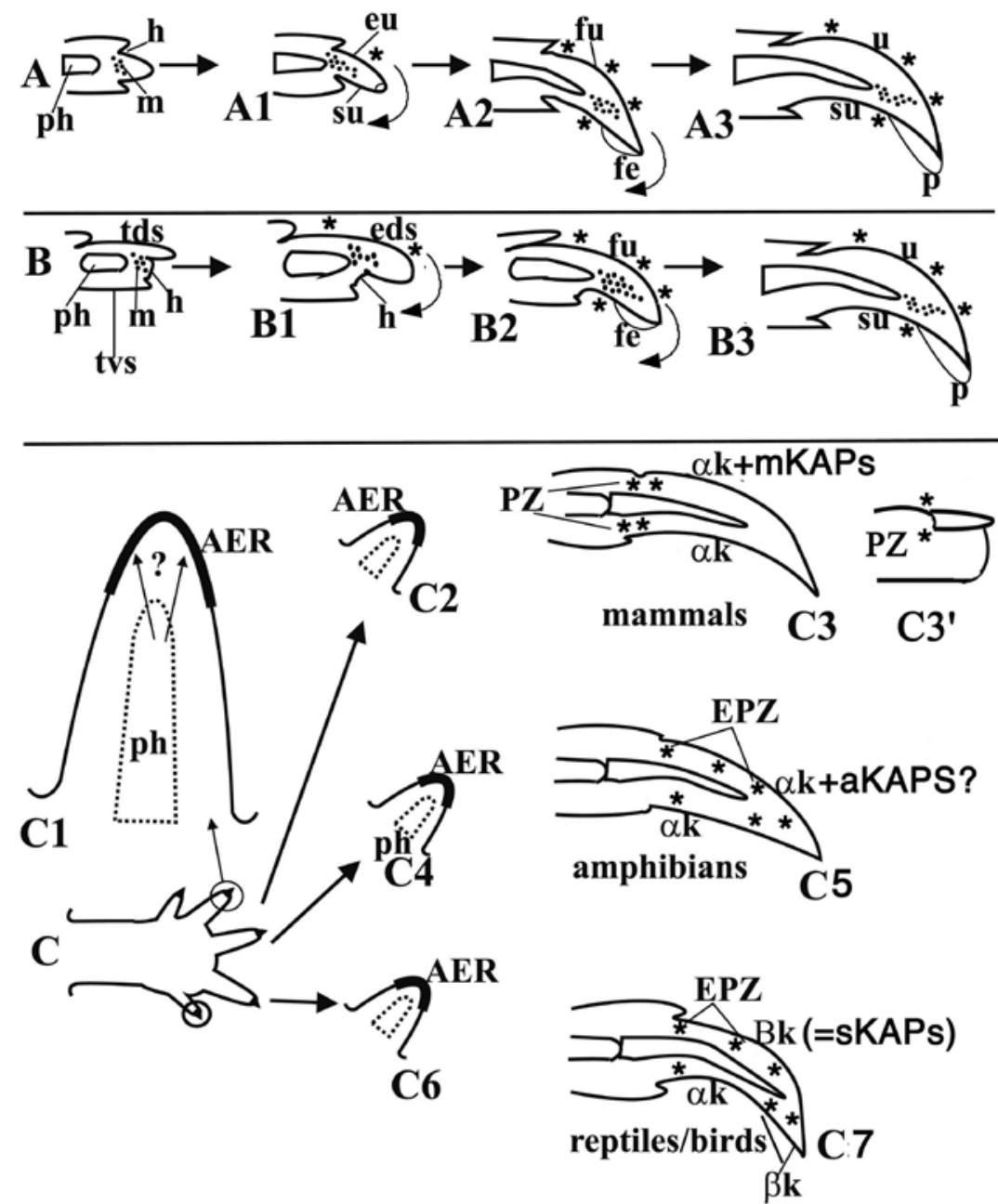

Fig. 10. Schematic drawing illustrating two hypotheses on the evolution of claws in reptiles (A-B) in comparison to the claws in other amniotes $(\mathbf{C})$ (see details in the text). In the first hypothesis (A), from a terminal, symmetric scale under influence of the mesenchyme associated with the last phalanx, one side of the scale elongates more than the other side (A1) determining the downward growth of the scale. The active mesenchyme grows in front of the terminal phalanx that elongates inside the forming claw (A2-A3). The overgrowth of corneous tissues over the tip of the claw determines the accumulation of a folded pad of embryonic epidermis, the transitory neonichium. In the second hypothesis (B), the claw derives from the elongation of the outer side of the terminal, dorsal scale of the digit under influence of the phalangeal mesenchyme (B1). The latter is in contact with the flat end of the digit that is occupied by a broad hinge region extended between the dorsal and ventral scales. The prevalent growth of the outer side of the dorsal terminal scale under the influence of the phalanx extends these scales over the tip of the digit. Also in this case, the overgrowth of corneous tissues over the tip of the claw forms the transitory neonichium. The formation of digits in developing embryos of reptiles (C) is related to the localized apical epidermal ridge at the tip of each digit (C1). The latter, potentially under the influence of the terminal phalanx (? Among the two arrows in C1), can produce the three different claws types found in mammals (C2-C3), reptiles/birds (C4-C5), and amphibians (C6-C7). While in mammals proliferating zones are mainly localized in dorsal, lateral and ventral matrix areas $(\mathbf{C 3})$, in reptiles/birds $(\mathbf{C 5})$ and likely also in amphibians $(\mathbf{C 7})$, the proliferating zones are extended to the whole length of the claw. While in mammals specific hair-like keratins are surrounded by keratinassociated proteins (HGT/HSP/UHSP), in reptiles and birds keratin associated proteins (formerly called beta-keratins) are rich in cysteine or glycine (HCPS/HGPS). In amphibians it is unknown whether keratin-associated proteins accumulate around specific claw alpha-keratins. Legends: AER, apical epidermal ridge; $\alpha \mathrm{k}$, alpha-keratins (tricocytic keratins); $\beta \mathrm{k}$, beta-keratins (now indicated as sKAPs); eu, elongating unguis; eds, extending dorsal scale; EPZ, extended proliferationg zone; fe, forming claw pad; fu, forming unguis; h, hinge region; mKAPs, mammalian Keratin Associated Keratins; m, mesenchyme; p, claw pad or neonychium; ph, phalanx; PZ, proliferating (matrix) zone; su, sub-unguis; sKAPs, sauuropsid Keratin Associated Keratins (= $\beta$-keratins); tds, terminal dorsal scale; tvs, terminal ventral scale.

mammalian nails whereas proximal growing regions (matrix) are instead present (Baden and Kvedar, 1983; see Fig. 10C-C7). Recent studies have also indicated that amphibian claws grow with a similar pattern than that of reptiles (Maddin et al, 2007, 2008; Alibardi, personal observations; Fig. 10C5).

The prevalent expansion of the unguis over the subunguis probably derives from a higher rate of cell proliferation that occurs in the dorsal side. This pattern in the lizard claw resembles the prevalent expansion of the developing outer side of normal scales (Alibardi, 1998, 2003, 2005). Part of the cells containing hard keratin produced from the unguis, move around the tip of the forming claw (curved arrows in Fig. 10A2, B2). This movement allows the coverage of the apical region of the sub-unguis, which is otherwise formed by cells with alpha-keratin like characteristics, including the presence of keratohyalin-like granules. The distal, 
curved movement of the apical hard-keratin cells is also indicated by the formation of the folded embryonic epidermis that gives rise to the ventral or sub-unguis pad in all species analyzed. This temporary region, which will be shed at hatching, is formed by inner periderm cells that accumulate coarse filaments of 20-22 $\mathrm{nm}$ diameter, organelles that are also present in embryonic layers of reptilian scales (Alibardi, 1998; Alibardi and Thompson, 1999a, b, 2001; Alibardi and Dipietrangelo, 2005; Alibardi and Gill, 2007).

The formation of this folded peg and of the hardkeratin type of conification of the unguis, suggest that the morphogenesis of the reptilian claw is a specific modification of the development from terminal scales of digits. Like in developing mammalian claws (Hamrich, 2001, 2003), also the morphogenesis of reptilian claws may be driven by the growth of the terminal phalanx (Fig. 10C-C1). This hypothetical influence in reptiles however remains to be proven and substantiated by molecular data.

The claw is initially covered by an embryonic epidermis consisting of an outer periderm involved in an intense exchange activity with the amniotic fluid, and by a multilayered inner periderm. These layers form the 'embryonic epidermis', a temporary tissue that will be lost around hatching. It is unexplained why the embryonic epidermis, normally formed by 2 layers of outer and inner periderm cells in embryonic scales, becomes thicker over tissues destined to form thick corneous layers made of hard keratin as in the claw or over scutes of the shell of turtles. The ultrastructural analysis of the embryonic layers confirms the presence of 25-40 nm thick coarse filaments, previously observed in embryonic epidermal cells of normal scales. The presence of these organelles in cells forming the ventral pad confirms that this region derives from the accumulation of embryonic epidermal cells coming from the sub-unguis and is contributed to by the migration of cells from the elongating unguis (see curved lines in Fig. 10A2, B2). The ventral pad of reptilian claws corresponds to the 'neonychium' or claw-pad of bird claws, a cushion of embryonic tissues suggested to prevent the damage on embryonic tissues caused by the presence of an unprotected, sharp claw tip (see Kerr, 1919; Alibardi, 2009a).

The dispersion of fine alpha-keratin filaments among coarse filaments produces a soft form of keratinization in the embryonic epidermis. In the claw no shedding layer is evident, including the claws of lizards, and corneocytes remain at least partially separated in the mature, external layers. Superficial cells may be lost either with a slow but continuous process of wearing or by a periodical shed similar to that reported for avian and mammalian claws (Cane and Spearman, 1967; Kreisa, 1979). The lack of a shedding complex in claws allows the accumulation of numerous layers of hard-keratin cells that merge into a compact and resistant corneous stratum.

The thinner keratinocytes in the inner side of the claw (sub-unguis) have been shown to possess mainly alpha-keratin cells characteristics of all reptilian groups. In fact, these cells flake off relatively easily, possess a corneous cell membrane, and contain small keratohyaline-like granules at the beginning of their differentiation. The alpha-type keratinocytes are more electron-dense than keratinocytes accumulating hard(beta-) keratin, and contain numerous tonofilaments but no beta-packets. The presence of lipid droplets, pale vesicles, and of extracellular lipids indicates these cells as alpha-keratinocytes. The cells are probably lost periodically and superficially like those present in the hinge region of normal scales. At later embryonic stages and in the adult claw, a thin and compact layer is also present in the sub-unguis, a condition also observed in avian claws (Lucas and Stettenheim, 1972). The presence of softer and harder corneocytes is probably related to the amount of keratinassociated proteins (or beta-keratins) accumulated in corneocytes during the process of cornification, as discussed in the next section.

\section{Cornification in reptilian claws in comparison to scales}

Beneath the embryonic epidermis, a definitive stratum corneum containing hard-keratin cells (formerly called beta-keratin cells) is formed well in advance of hatching. The formation of hard-keratin cells in the claw prior to the development of beta-cells in the scales of the skin remains to be explained. Also, it is unclear why hard-keratinocytes remain discrete cells in the stratum corneum of the claws while they tend to merge into a sincytium in the scale. This process may be related to the lack of a shedding layer in claws while a shedding layer is present in the epidermis of scales in lepidosaurians (Maderson, 1985; Alibardi, 2008b). While the evolution of the scale epidermis has progressed toward the improvement of a scission (shedding) layer in lepidosaurians, the functional demand of the claw requires an increase in the thickness of the stratum corneum. Therefore a shedding layer is not formed and the claw surface is worn with use or may be lost in irregular flakes in some periods, although the latter process has 
not been histologically documented from the available literature. The mechanism that determines this difference between claws and normal scales (where a shedding layer is formed) remains unknown.

The present study has shown that hard-keratin cells of claws possess a variable shape, elongation and dimension in different species of lizards, Sphenodon, alligator and turtles. Keratinizing cells are fusiform in all species but they tend to elongate in some species more than in others. In claws of some lizards (Lampropholis and Podarcis) hard-keratin cells have a spindleshape and accumulate hard-keratin in the form of an irregular mass, as in normal scales. These filaments have a prevalent parallel disposition and are orientated along the longitudinal plane of the digit, roughly parallel with respect to the epidermis surface. This prevalent orientation of bundles of keratin also occurs in the mammalian nail, which consists of hair-like keratins and in matrix or keratin associated proteins (Baden, 1970; Gillespie, 1991; Rogers, 2004).

In the claw of S.punctatus Gray 1842 and in that of the alligator, corneous cells become quite elongated and they stick together at the apex of the claw to form the pointed tip. A further elongation of corneocytes is seen in the beta-layer of the claw in A. lineatopus Gray 1840 where cells accumulate long and parallel bundles of hard (beta-) keratin. After incorporation into the stratum corneum these cells stick together and largely merge with each other into a compact corneous layer. This type of cornification may also occur for the claw in other iguainid lizards, such as A. carolinensis Duméril and Bribon 1837 (Alibardi, personal observations) and Crotaphytus collaris Say 1823 (see Fig. 2 in Maddin et al., 2007).

A process of extreme cell elongation is observed in specialized digital scales localized near the claw, in the digital adhesive lamellae of anoline lizards. The latter represent a gripping device that improves the (primitive) claw grip. The resemblance of elongating betacells in claws of iguanid lizards with setae of the nearby pad lamellae suggests that while claws evolved by fusion of these elongated corneous cells, pad lamellae evolved by separating the elongated cells through the interposition of cells of the clear layer. The bundles of hard-keratin are oriented along the main axis of these cells, a process that resembles that of elongating barbule cells of feathers.

In conclusion, the different growth patterns in amphibian, reptile, bird, and mammalian claws appears related to their specific skin derivation (Fig.10 C2-C7). The derivation from a scale indicates that reptilian and avian claws are not homologous to claws in either amphibians or mammals that are not derived from scales. Therefore in reptiles and birds, claws obtain their pattern of growth from the pattern of growth in scales in which proliferating cells are mainly found in the outer scale surface. The latter becomes the unguis while the sub-unguis, like the inner surface of body scales, shows a lower number of dividing cells. Different from reptiles, mammalian claws grow from proximal centers of cell proliferation, termed matrix zones, linked with the evolution of a proximal groove with an associated dermal papilla. Therefore in tetrapods claws are corneous structures that evolved by a process of convergence associated with the growth of the last phalanx, and permitted grasping, clinging, manipulation, offence and defence.

\section{Acknowledgements}

The present study was largely conducted with personal funding. Dr. Mattia Toni helped make figure 10, using the Corel Draw Program 11.

\section{References}

Alibardi L. 1998. Glycogen distribution in relation to epidermal cell differentiation during embryonic scale morphogenesis in the lizard Anolis lineatopus. Acta Zoologica 79: 91-100.

Alibardi L. 2003. Ultrastructural autoradiographic and immunocytochemical analysis of setae formation and keratinization in the digital pads of the gecko Hemidactylus turcicus (Gekkonidae, Reptilia). Tissue and Cell 35: 288-296.

Alibardi L. 2005. Proliferation in the epidermis of chelonians and growth of the horny scutes. Journal of Morphology 265: 52-69.

Alibardi L. 2008a. Microscopic analysis of lizard claw morphogenesis and hypothesis on its evolution. Acta Zoologica 89: 169-178.

Alibardi L. 2008b. Cornification in developing claws of the common Australian skink (Lampropholis guichenoti) (Squamata, Lacertidae). Italian Journal of Zoology 75: 327-336.

Alibardi L. 2009a. Ultrastructural characteristics of the process of cornification in developing claws of the brush tail possum (Trichosurus vulpecula). Acta Zoologica (in press).

Alibardi L. 2009b. Claw development and cornification in the passeraceous bird zebrafinch (Taeniatopygia guttata castanotis). Anatomical Science International (in press).

Alibardi L, Thompson MB. 1999a. Epidermal differentiation in the developing scales of embryos of the Australian scincid lizard Lampropholis guichenoti. Journal of Morphology 241: 139-152.

Alibardi L, Thompson MB. 1999b. Epidermal differentiation during carapace and plastron formation in the embryo of the turtle Emydura macquarii. Journal of Anatomy 194: 531545. 
Alibardi L, Thompson MB. 2001. Fine structure of the developing epidermis in the embryo of the american alligator (Alligator missippippiensis, Crocodilia, Reptilia). Journal of Anatomy 198: 265-282.

Alibardi L, Dipietrangelo L. 2005. Differentiation of the epidermis of scutes in embryos and juveniles of the tortoise Testudo hermanni with emphasis on beta-keratinization. Acta Zoologica 86: 205-216.

Alibardi L, Gill BJ. 2007. Epidermal differentiation in embryos of the tuatara Sphenodon punctatus (Reptilia, Sphenodontidae) in comparison with the epidermis of other reptiles. Journal of Anatomy 211: 92-103.

Alibardi L, Toni M. 2009. Immunocytochemistry and protein analysis suggest that reptilian claws contain small highcysteine-glycine proteins. Tissue and Cell 41: 180-192.

Baden PH. 1970. The physical properties of nail. Journal of Investigative Dermatology 55: 115-122.

Baden HP, Kvedar JC. 1983. The nail. In: Goldsmith LA, Ed. Physiology, Biochemistry and Molecular Biology of the Skin, vol 1. New York-Oxford: Oxford University Press, 697-711.

Bragulla H. 2003. Fetal development of the segment-specific papillary body in the equine hoof. Journal of Morphology 258: 207-224.

Bragulla H, Hirschberg RM. 2003. Horse hooves and bird feathers: two model systems for studying the structure and development of highly adapted integumentary accessory organsThe role of dermo-epidermal interface for the micro-architecture of complex epidermal structures. Journal of Experimental Zoology 298 B: 140-151.

Cane AK, Spearman RIC. 1967. A histochemical study of keratinization in the domestic fowl (Gallus gallus). Journal of Zoology (London) 153: 337-352.

Chapman RE. 1986. Hair, wool, quill, nail, claw, hoof and horn. In: Bereither-Hahn J, Matoltsy GA, Sylvia-Richards K, eds. Biology of the integument, Vertebrates, vol. 2. Berlin, Heidelberg, New York: Springer-Verlag. 293-312.

De Berker D, Angus B. 1996. Proliferative compartments in the normal nail unit. British Journal of Dermatology 135: 555559.

Dufaure JP, Hubert J. 1961. Table de developpement du lezard vivipare: Lacerta (Zootoca) vivipara Jacquin. Archives des Anatomie Microscopique et Morphologie Experimentelle 50: 309-327.

Ferguson MW. 1987. Post-laying stages of embryonic development for crocodilians. In: GJW Webb, Manolis CS, and Whitehead PJ, Eds. Wildlife management: crocodiles and alligators. NT: Surrey Beatty \& Sons Pty. 427-444.

Gillespie JM. 1991. The structural proteins of hair: isolation, characterization and regulation of biosynthesis. In: Goldsmith LA, Ed. Physiology, Biochemistry and Molecular Biology of the Skin. Oxford: Oxford University Press, 625-659.

Hamrich MW. 2001. Development and evolution of the mammalian limb: adaptive diversification of the nail, hooves, and claws. Evolution and Development 3: 355-363.

Hamrich MW. 2003. Evolution and development of mammalian limb integumentary structures. Journal of Experimental Zoology 298B: 152-163.

Hashimoto K. 1971. Ultrastructure of the human toenail. II. Keratinization and formation of the marginal band. Journal of Ultrastructural Research 36: 391-410.
Hashimoto K, Gross BG, Nelson R, Lever WF. 1966. The ultrastructure of the skin of human embryo. III. The formation of the nail in 16-18 weeks old embryos. Journal of Investigative Dermatology 47: 205-217.

Kato T. 1977. A study on the development of the cat claw. Hiroshima Journal of Medical Sciences 26: 103-126.

Kerr JG. 1919. Text-book of embryology, Vol II, Vertebrata. London: MacMillian and Co., 69-77.

Kreisa RJ. 1979. The comparative anatomy of the integumental skeleton. In: Wake MH, editor. Hyman's comparative vertebrate anatomy, 3rd edition. Chicago \& London: The University of Chicago Press. 112-191.

Landmann L. 1986. The skin of Reptiles. Epidermis and Dermis. In: Bereiter-Hahn J, Matoltsy AG, and Sylvia-Richards K., Eds. Biology of the integument, vol 2. Vertebrates. Berlin and New York: Springer-Verlag, 150-187.

Lucas AM, Stettenheim PR. 1972. Growth of follicles and feathers. Color of feathers and integument. In: Avian anatomy. Integument. Agriculture Handbook 362, Chapter 7. Washington DC: US Department of Agriculture, 341-419.

Maderson PFA. 1985. Some developmental problems of the reptilian integument. In: Gans C, Billett F and Maderson PFA, Eds. Biology of Reptilia, vol. 14B. New York: John Wiley \& Sons. 525-598.

Maddin HC, Reisz RR. 2007. The morphology of the terminal phalanges in Permo-Carboniferous synapsids: an evolutionary perspective. Canadian Journal of Earth Science 44: 267-274.

Maddin HC, Musat-Marcu S, Reisz RR. 2007. Histological microstructure of the claws of the africn clawed frog, Xenopus laevis (Anura: Pipidae): implications for the evolution of claws in tetrapods. Journal of Experimental Zoology 308B: $1-10$.

Maddin HC, Eckhart L, Jaeger K, Russel AP, Ghannadan M. 2008. Anatomy and development of the claw of Xenopus laevis (Lissamphibia: Anura) reveal alternative pathways of structural evolution in the integument of tetrapods. Journal of Anatomy 212 (in press).

Rogers GE. 2004. Hair follicle differentiation and regulation. International Journal of Developmental Biology 48: 163 170 .

Spearman RIC, Hardy JA. 1985. Integument. In: King AS, McLelland J, Eds. Form and function of birds. vol. 3. London: Academic Press Inc. 1-56.

Wu P, Hou L, Plikus M, Hughes M, Scehnet J, Suksaweang S, Widelitz RB, Jiang TX, Chuong CM. 2004. Evo-devo of amniote integuments and appendages. International Journal of Developmental Biology 48: 249-270.

Yntema CL. 1968. A series of stages in the embryonic development of Chelydra serpentina. Journal of Morphology 125: 219-251.

Zaias N, Alvarez J. 1968. The formation of the primate nail plate. An autoradiographic study in squirrel monkey. Journal of Investigative Dermatology 51: 120-136.

Received: 7 January 2009

Accepted: 13 March 2009

Published online: 18 May 2009

Edited: J.W. Arntzen 